\title{
A Study on the Development of a Fleet Management System for Construction Equipment
}

\author{
So Young Lim and Sung Keun Kim \\ School of Civil Engineering, Seoul Nation University of Science and Technology, Seoul, Korea
}

\begin{abstract}
In the construction industry, an earthwork highly dependent on construction equipment is a sort of decision-making process which is performed to establish an efficient work plan and construction plan of a fleet of construction equipment moving in and out of a construction site and to make work instructions in real time. The system of delivering a decision made to each equipment operator is aimed at achieving field management with the efficient and stable control of construction equipment. By suggesting the optimal equipment combination, soil distribution and a moving path of individual equipment in consideration of earthworks which are performed with the cooperation of multiple equipment, it is possible to create a work plan of earthwork equipment actively. If the construction equipment management system technology based on construction equipment fleet management and smart construction technology are applied to earthwork projects, it is expected to bring about fast, accurate and safe construction and thereby to increase productivity.
\end{abstract}

Key words: Earthwork, soil distribution, planning, fleet management, path planning, projects

\section{INTRODUCTION}

Background and purpose of research: Unlike other industries, the construction industry is highly dependent on labor force and mechanical construction in projects. The construction industry, one of $3 \mathrm{D}$ industries, face failure of the inflow of young labor force has difficulty securing skillful technicians. Therefore, it is important to operate efficient construction equipment. In large earthworks that mainly include mechanical construction, optimal soil distribution and plan based field operation greatly influence the productivity of the whole earthwork. For this reason, many efforts are made to overcome various kinds of problems that the construction industry face. Many experts on their areas try to find a solution by researching construction automation. In the US and Japan, empirical research on construction automation has been conducted for the purpose of construction automation in sites. To respond to changing circumstances in the construction industry, there has been an active trial to introduce new technology and new engineering techniques in interaction with other areas.

The current problem of field management is that the operation planning of construction equipment is dependent on field worker's intuition and experiences. To solve the problem, it is necessary to share information between workers in real time and perform work operation. Therefore, efficient soil distribution in consideration of field conditions and a construction equipment fleet management system for construction equipment operation (Ahn et al., 2016) were developed. To improve the problems of the developed system, the study (Kim and Lim, 2017) had been conducted.

The improved fleet management system provided information with the use of a server module and a mobile module in order to overcome the problem of real-time transmission between a work information manager and an operator and improved the automatic conversion module of map coordinates for establishing an earthwork plan and offering information to a 3D scan map in real time. In addition, the algorithm for effective matching of a filling zone and a cutting zone was improved, so as to suggest a module that generates a grid mesh in a construction site at the time of establishing an earthwork plan and creates a path to move construction equipment. Therefore, regarding the problem that the central coordinates of cutting and filling are simply moved in a straight line when construction equipment is moved, the improved system avoids non-passable zones and suggest an actual equipment movable path. Aside from that, the actual field conditions were applied to a moving path of a dump truck in order to increase field applicability of the system. After the improved system was applied to a field, equipment operators required simpler information delivery. The fleet management system for construction equipment that continues to be debugged is expected to greatly

Corresponding Author: So Young Lim, School of Civil Engineering, Seoul Nation University of Science and Technology, Seoul, Korea 
contribute to improving the productivity of field operation through soil distribution and efficient operation of construction equipment at a construction site (Anonymus, 2015).

Scope and method of research: The scope of this study is to offer the methodology for improving field applicability of the already developed fleet management system for construction equipment, to develop the hardware and software for an improved fleet management system and to conduct a field test for performance. A target construction type is a large earthwork complex site and the construction equipment for fleet operation is limited to an excavator and a truck. More detailed research scope and method are presented as:

Analysis on relevant technology trends: This study analyzes the research trends of construction automation at sites in advanced countries and current fleet management systems. Today, a large amount of investments are made in the development of a construction equipment management system through convergence of the cutting-edge technology and construction technology. Therefore, related problems are also, investigated (Easa, 1992).

Simple information offering of fleet management system in consideration of heuristic aspect: In the construction equipment fleet management system for efficient soil distribution and construction equipment operation in consideration of field conditions (Ahn et al., 2016; Kim and Lim, 2017; Easa, 1993) to improve the problems of the developed system, equipment operators raise an opinion in a field test that they had difficulty recognizing information due to information diversity. Therefore, in consideration of the heuristic aspect of equipment operators information simplification is suggested (Easa, 1998).

Soil distribution of optimal operation system: In the improved fleet management system, cutting group and filling group are suggested. The problem is that such a method is simply based on an amount of earthwork and a distance. Therefore, this study applied soil distribution through density based grouping and tried to suggest a system application algorithm on the basis of a different distance and a type of equipment (Ahn et al., 2016).

\section{MATERIALS AND METHODS}

Analysis on domestic and Foreign technology trends Actual conditions of construction equipment operation at construction sites: The US CMU developed Autonomous
Loading System (ALS) as the first unmanned autonomous excavation system in 1999 whichhas become the basis of the application of a variety of earthwork equipment. The global construction market expects to grow $14.5 \%$ annually on average by 2030 and the sales of construction equipment are predicted to rise $24 \%$. As telematics programs for applying construction equipment to the earthwork of a large complex in the world, there are "Fleetwatcher" of earthwave Technologies, "VisionLink" of Catapillar and "Sitelink" of Topcon. The earthwork automation system of Trimble updates in real time the positioning information of earthwork equipment with the use of a GPS and displays CAD design information on the monitor of equipment in order to provide information on cutting and filling positions to an equipment operator. RFID (Radio Frequency Identification), GPS (Global Positioning System) and UWB (Ultra Wide Band) which are based on the radio frequency technology were applied to the real-time positioning system for a construction site which was developed by Georgia Tech. The developed system was evaluated to provide useful information for productivity analysis and process management at a construction site. Domestically, to improve efficiency of construction equipment, a filed situation was controlled through tracking of excavation equipment and "3D-MC" technology of Japanese Sokkia for presenting how each excavation equipment makes a construction was used to make a construction site construct a site. Since, there is no domestic relevant technology, the development of the domestic technology specialized for a domestic site is expected to lead to rising demands of field management with the use of the technology (Kim, 2014).

Current fleet management system technology: To apply information on equipment move at a site in real time, a fleet management system has the function of entering attributes of each cell's moving path installed. To support a field worker's decision making, it provides a screen. A simulator is divided into a planning module and an execution module. The planning module performs soil distribution and resource allocation and management. The execution module supports the path guidance to support the decision making of a field earthworker (dump truck driver) (Kim and Lim, 2017; Baek et al., 2015).

A fleet management system does not need the human resources for surveying and recording signals and equipment operation, the factors which are dependent on human resources when equipment operation is performed at a site. The system based equipment operation helps to increase productivity, to reduce $\mathrm{CO}_{2}$ emissions and solve the problem of safety accidents caused by non-deployment of human resources (Kim et al., 2012). 


\section{RESULTS AND DISCUSSION}

Fleet management system algorithm: To maximize productivity of multiple types of a lot of construction equipment used at a large earthwork site, it is essential to apply a fleet management system, to determine the equipment's moving path in consideration of real-time changing field conditions and to calculate the optimal number of equipment for future earthworks.

In an earthwork site, diverse variables occur momently. It is hard to control and instruct them with the simple calculation of the system. In factories, if some processes have problems or it is necessary to reduce a production amount, it is possible to stop running some equipment to improve productivity. In an earthwork site, if the construction equipment used on the day stops running in the way of work, the machine and labor costs for construction equipment should be paid by a constructor. As such, the operation of construction equipment is directly related to economy and productivity. Unfortunately in terms of the use of construction equipment for an earthwork, the number of construction equipment to be used in the next day is calculated by rule of thumb on the basis of a constructor's experience and the equipment is operated carelessly to achieve the goal of work assignment. Equipment operators have overspeed driving to achieve their work goal. As a result, safety accidents often occur every year.

To operate a fleet of construction equipment in high productivity, it is necessary to work without equipment idling. To do that, it is required to calculate the optimal number of equipment and suggest an optimal path. The program for such things needs to be developed in four categories: earthwork volume calculation and earthwork
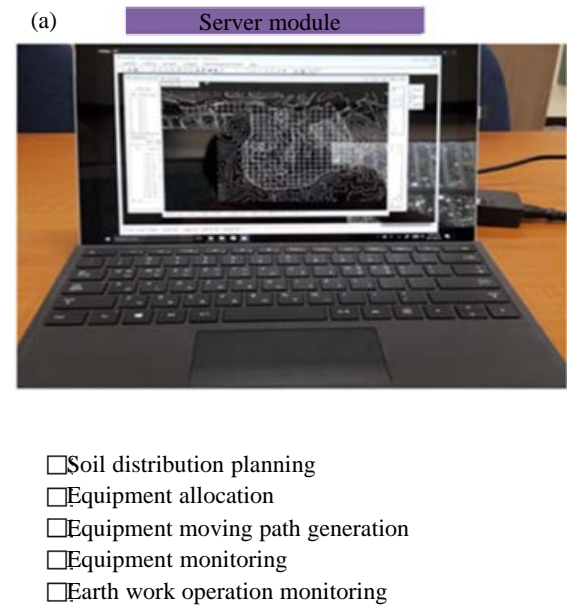

planning, an optimal path of each equipment, the calculation of the optimal number of construction equipment and real-time regrouping of a fleet.

Simplification of the offered information of fleet management system considering heuristic aspect: $A$ server module establishes a plan of soil distribution and provides information on the composition of a fleet of construction equipment. A mobile module for construction equipment provides a work path and a real-time position of construction equipment for an operator. It provides information on work state and the function of requesting the new fleet composition of construction equipment. The complaints raised by equipment operators at the time of their use of this system at a site were collected. According to the analysis on the complaints, there was no problem, since, the information offered by the server module was for a field chief manager, rather than an operator. In case of a mobile module, both excavator operators and dump truck drivers simply required a path display and a work volume. In consideration of heuristic aspect, the mobile module shown in Fig. 1 tries to provide a moving path of equipment and a work volume.

Clustering algorithm of earth distribution: To solve the problem that soil distribution clustering relies on the experience for a factor value, OPTICS algorithm calculates gradual cluster ordering with automatic interaction, rather than explicit data set clustering. This ordering represents the data density based clustering structure and includes the information on the clustering based on density obtained from a wide range of factor setting. When a set of points involved in $\mu$, cluster, the centroid of ith cluster is $\mathrm{S}$, the total variance is presented as in Eq. 1:

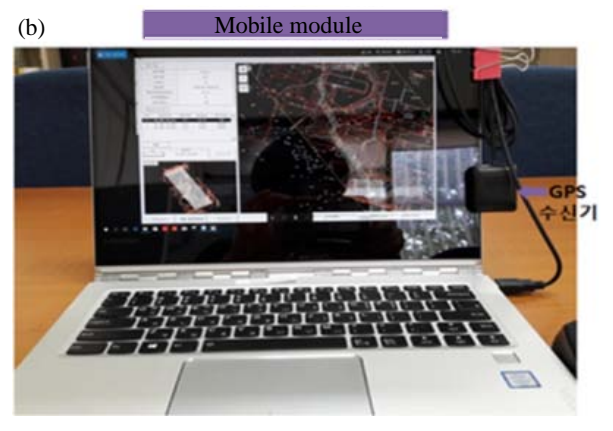

- Excavator

$\square$ Soil gathering and cutting o truck

$\square$ Soil transportation and embankment

Fig. 1: a, b) Earth distribution algorithm at $<50 \mathrm{~m}$ of earth moving 


$$
\mathrm{V}=\sum_{\mathrm{i}=1}^{\mathrm{k}} \sum_{\mathrm{j} \in \mathrm{s}_{\mathrm{i}}}\left|\mathrm{x}_{\mathrm{i}}-\mu_{\mathrm{i}}\right|^{2}
$$

OPTICS algorithm aimed at finding $\mathrm{S}$ to minimize the value begins with the course of setting up the initial $\mu$. Cluster setting: data is allocated in the order of $\mu$ dual distance from each data to each cluster:

$$
\mathrm{S}_{\mathrm{i}}^{(\mathrm{t})}=\left\{\mathrm{x}_{\mathrm{p}}:\left|\mathrm{x}_{\mathrm{p}}-\mu_{\mathrm{i}}^{(\mathrm{t})}\right|^{2} \leq\left|\mathrm{x}_{\mathrm{p}}-\mu_{\mathrm{j}}^{(\mathrm{t})}\right|^{2} \forall \mathrm{j}, 1 \leq \mathrm{j} \leq \mathrm{k}\right\}
$$

Resetting of the centroid of cluster: reset to the center of gravity of data in each cluster:

$$
\mu_{1}^{(t+1)}=\frac{1}{\left|S_{i}^{(t)}\right|} \sum_{\mathrm{x}_{\mathrm{j}} \in \mathrm{S}_{\mathrm{i}}^{(t)}} \mathrm{x}_{\mathrm{j}}
$$

If there is no cluster change, repetition stops. The inputs of the algorithm are the number of clusters $(\mathrm{k})$ and a set of $\mathrm{n}$ data objects (D) and its output is k clusters. From the data object set ' $\mathrm{D}$ ', $\mathrm{k}$ data objects are randomly extracted and these data objects are set as the centroid of each cluster. This is the process of setting an initial value. For each data object in the set $\mathrm{D}$, the distance with each one of $\mathrm{k}$ cluster centroid objects is calculated, so as to find a centroid which has the highest similarity with each data object. And with the centroid found, each object data is allocated.

The centroid of clusters is recalculated. In other words with the clusters re-allocated in No. 2 a centroid is calculated again. The No. 2 and 3 processes are repeated until the cluster of each data Object is not changed.

\section{Initial value setting algorithm:}

- One random data is selected from a data set and is set as the first centroid

- Until $\mathrm{k}$ centroids are selected, the following procedure is repeated

- For each data in the data set, the distance $D(x)$ between a relevant data and its closest centroid is calculated

- With the use of bias probability distribution in which a probability is proportionate to $\mathrm{D}(\mathrm{x})^{2}$, a random data is selected and is set as the nth centroid

The selected $\mathrm{k}$ centroids are set as initial values and then $\mathrm{k}$-means clustering is performed.

Alternative for k-means limitation: In the condition where each one of $n$ objects have $p$ variables, the jth variable of the object $i$ is set to $X_{i}(i=1, \ldots, n ; i=1, \ldots, p)$ and all objects are classified into $\mathrm{k}$ clusters, the proposed algorithm is presented as follows:

Algorithm 1; All objects are classified into k clusters: Step 1: Select an initial representative object

Given Euclidean distance as dissimilarity measure, the distance of all objects is calculated as follows:

$$
d_{i j}=\sqrt{\sum_{\alpha=1}^{p}}\left(X_{i \mathrm{in}}-X_{j \alpha}\right)^{2} i=1, \ldots, n j=1, \ldots, n
$$

To select an object located at the center, calculation is performed as follows:

$$
P_{i j}=\frac{d_{i j}}{\sum_{i=1}^{n} d_{i j}} i=1, \ldots, n j=1, \ldots, n
$$

For each object $\sum^{\mathrm{n}} \mathrm{d}_{\mathrm{i}}$ is calculated and an array is made. After that, $\mathrm{k}$

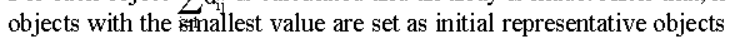
For an object not selected as a representative object, the object is assigned to the closest representative object

The total of distances between each cluster's representative object and all objects in the cluster is set as the current optimal value

Step 2: In terms of the calculation of a new representative object, the object with the minimum total of distances between objects in the same cluster is selected as a new one

Step 3: New cluster assignment

3-1. For an object not selected as a representative object, the object is assigned to the closes cluster

3-2. The total of distances between a representative object and all objects of its cluster is set as a new optimal value. If the new value is equal to the previous one, the algorithm ends, otherwise, it goes back to Step 2

Algorithm by earth distribution distance: To calculate the optimal number of equipment, it is necessary to judge a daily work volume. To calculate a transport earthwork amount, it is necessary to divide a cutting zone and a filling zone exactly and plan a moving path of earth clearly. In this way, it is possible to predict the optimal number of equipment necessary for the day.

In case of earth moving in Korea, the equipment in need is dependent on as to whether a moving distance of earth exceeds $50 \mathrm{~m}$. If the distance is $<50 \mathrm{~m}$, a grader or a dozer is utilized if more than $50 \mathrm{~m}$, the combination of an excavator and a dump is applied. Accordingly, in this system, earthwork planning module is divided into two steps. If a moving distance of earth is $<50 \mathrm{~m}$, the algorithm of Fig. 2 is applied for earth distribution.

A site is specified to generate a mesh. A cutting zone, a filling zone and no change of earth with null value are generated. A cutting zone, a filling zone and an intermediate collection zone have multiple-tomultiple matching. A zone that needs more than $50 \mathrm{~m}$ goes to the next step. Earth with $<50 \mathrm{~m}$ of moving is transported and then whether the value after the 1 st 


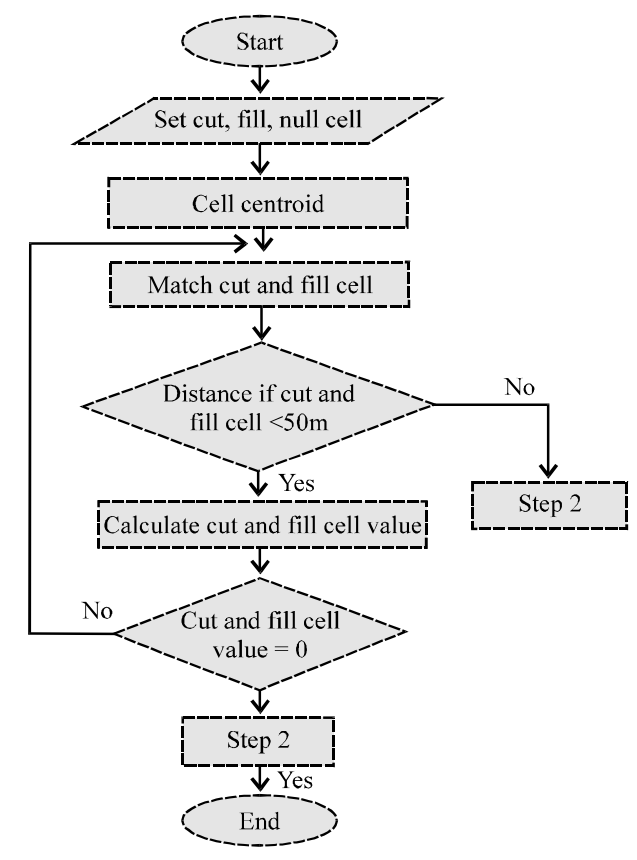

Fig. 2: Earth distribution algorithm at $<50 \mathrm{~m}$ of earth moving

moving is ' 0 ' is checked. If it is not ' 0 ', multiple-tomultiple matching is performed again In this way, the earth distribution work scenario for $<50 \mathrm{~m}$ of earth moving is created.

Primarily, if the earth distribution with a short distance whichmeans that earth can be moved with the use of a dozer, comes to an end, the algorithm for long-distance earth moving in combination with an excavator and a dump is executed as in Fig. 3.

In case of mid-and long-distance earth distribution, an intermediate collection zone, a cutting zone and a filling zone are differentiated and have multiple-to-multiple matching which is repeated until the value of the cutting zone or the filling zone is ' 0 '. After earth distribution and moving plan is completed, if an earthwork volume which was not found in the short-distance algorithm appears in the mid-and long-distance earth moving, the earth is moved along with long-distance earth moving. In this way, long-distance earth moving process is generated. This process uses Fast Track technique in the similar principle of multiple processing programs.

Algorithm for the optimal path by equipment type: Regarding the systems suggesting an optimal path, general vehicles obtain an optimal path through their navigation system, so that such a system is friendly enough to drivers. However, there is no separate

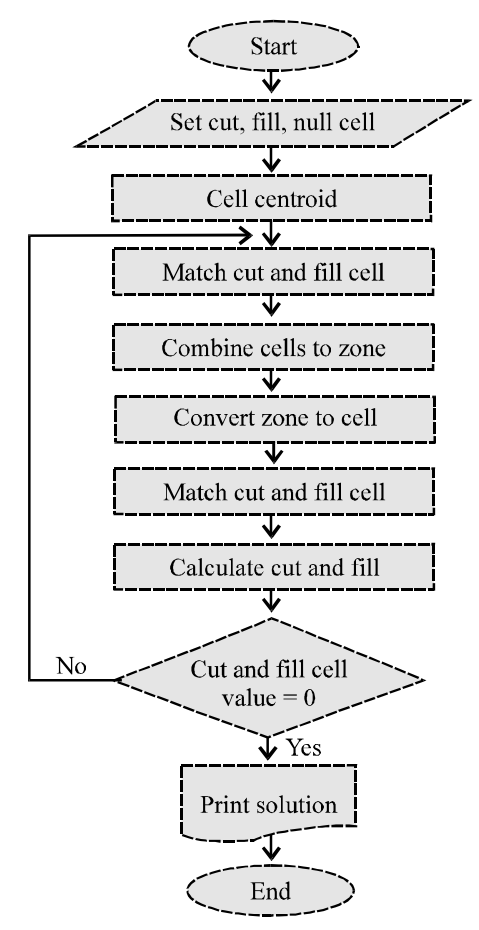

Fig. 3: Earth distribution algorithm at more than $50 \mathrm{~m}$ of earth moving

development of a navigation system for construction equipment. As a result, equipment is moved under an operator's personal judgment. When equipment was moved under their personal judgment, loading and unloading times were similar. Nevertheless, a moving was different every time so that a cycle time was not constant, productivity was lowered and overspeedy construction equipment led to a safety accident. Therefore, to secure constant productivity of construction equipment, this study applied the system suggesting an optimal path. The optimal path algorithm is presented as in Fig. 4.

An optimal moving path (a start point and an end point) of a dozer, an excavator or a dump is created according to the moving path of earth distribution which is obtained from earth distribution algorithm. A zone where construction equipment is unable to move is selected first. And then, the shortest path from a start point and an end point in movable zones is suggested. If there are multiple shortest paths, a gradient is analyzed in consideration of fuel efficiency. As a result, the shortest path with a small gradient is suggested.

Algorithm for calculating the optimal number of equipment: Based on the earth moving plan established in earth distribution process, the optimal number of equipment is calculated. To set a daily work volume, it is 


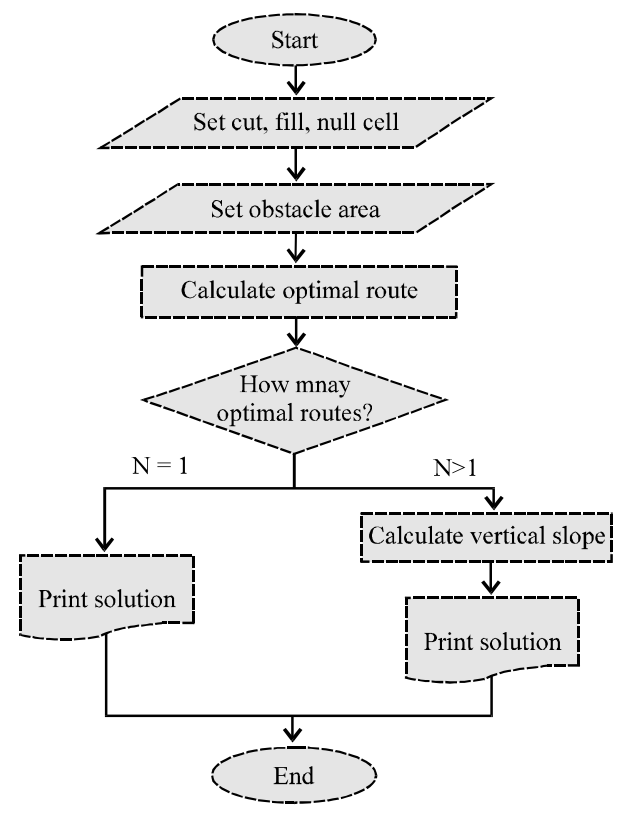

Fig. 4: Algorithm for an optimal path

required to calculate a one-day work volume on the basis of the work volume applied in a standard of estimate. When it comes to the equipment for earth moving, a dozer is utilized for a short distance and an excavator and a dump for a mid and long distance. The daily work volume for each equipment type is calculated in Eq. 6-8.

\section{Dozer's work volume per hour:}

$$
\mathrm{Q}=\frac{60 \square \mathrm{a} \square \mathrm{f} \square \mathrm{E}}{\mathrm{C}_{\mathrm{m}}}
$$

Where:

$$
\begin{aligned}
\mathrm{q} & =\text { Capacity of a spades blade }\left(\mathrm{m}^{3}\right) \\
\mathrm{f} & =\text { Soil conversion factor } \\
\mathrm{E} & =\text { Work efficiency } \\
\mathrm{C}_{\mathrm{m}} & =\text { One-time cycle time }(\mathrm{min})
\end{aligned}
$$

\section{Excavator's work volume per hour:}

$$
\mathrm{Q}=\frac{3600 \square \mathrm{a} \square \mathrm{k} \square \mathrm{f} \square \mathrm{E}}{\mathrm{C}_{\mathrm{m}}}
$$

Where:

$$
\begin{aligned}
\mathrm{q} & =\text { Bucket capacity }\left(\mathrm{m}^{3}\right) \\
\mathrm{k} & =\text { Bucket conversion factor } \\
\mathrm{f} & =\text { Soil conversion factor } \\
\mathrm{E} & =\text { Work efficiency } \\
\mathrm{C}_{\mathrm{m}} & =\text { One-time cycle time }(\mathrm{sec})
\end{aligned}
$$

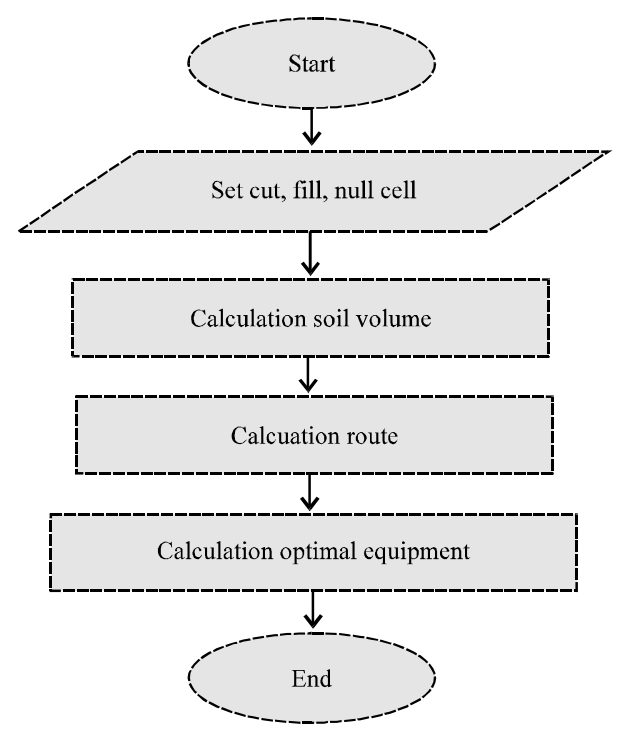

Fig. 5: Algorithm for calculating the optimal number of equipment

\section{Dump's work volume per hour:}

$$
\mathrm{Q}=\frac{3600 \square \mathrm{a} \square \mathrm{k} \square \mathrm{f} \square \mathrm{E}}{\mathrm{C}_{\mathrm{m}}}
$$

Where:

$$
\begin{aligned}
\mathrm{q} & =\text { Bucket capacity }\left(\mathrm{m}^{3}\right) \\
\mathrm{k} & =\text { Bucket conversion factor } \\
\mathrm{f} & =\text { Soil conversion factor } \\
\mathrm{E} & =\text { Work efficiency } \\
\mathrm{C}_{\mathrm{m}} & =\text { One-time cycle time }(\mathrm{min})
\end{aligned}
$$

Based on each equipment's work volume per hour, a proper daily work volume is calculated. The cycle time in consideration of earth moving process and equipment's moving path and planned work days for earth moving are taken into account in order to calculate the optimal number of equipment needed for one day. The algorithm for calculating the optimal number is illustrated in Fig. 5.

Field test of fleet management system: Conventional earthworks have been performed with construction equipment operator's experience and intuition. The developed fleet management system provides information to operators in order to work on the basis of an optimal work plan and optimal path of each construction equipment and thereby can improve productivity and economy of earthworks.

The field test results of this fleet management system are presented below. The system was applied to three sites: Chungbook Eunam Industrial Complex Site, Ulsan Onsan Industrial Complex Site and Damyang Advanced 
(a)

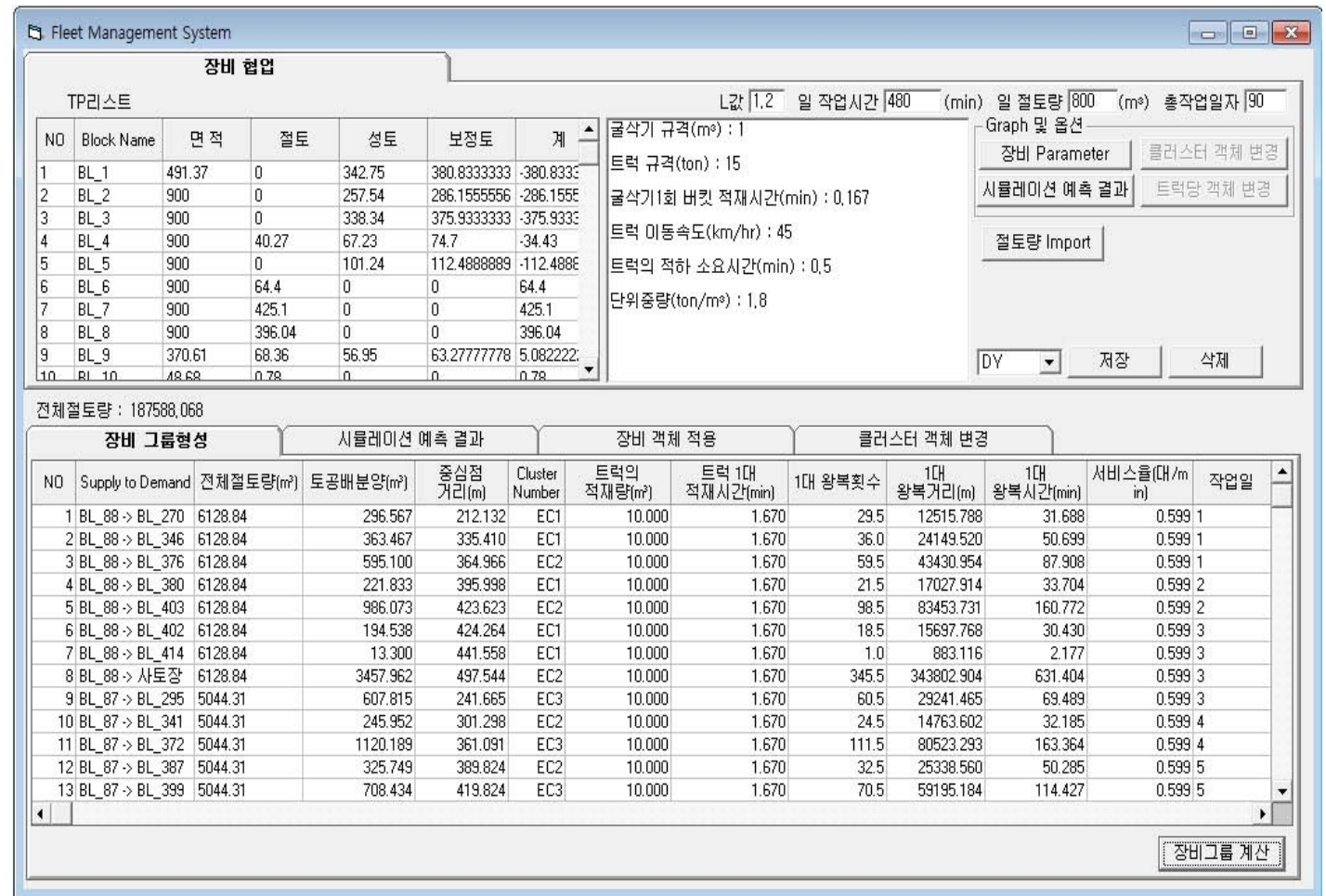

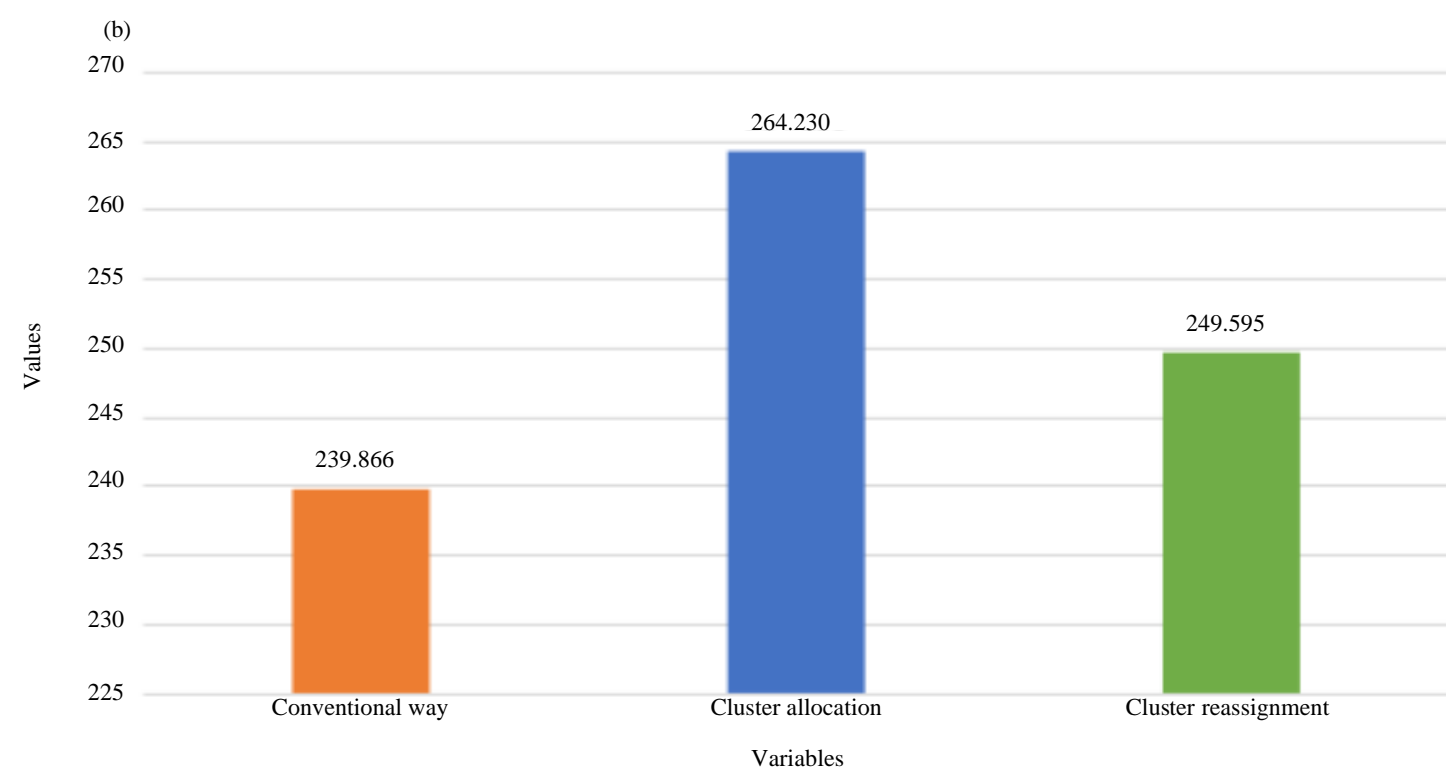

Fig. 6: a, b) The result of the application of fleet management system to Eunam Industrial Complex Site; Work per cluster average hour $\left(\mathrm{m}^{3} / \mathrm{h}\right)$

Industrial Complex Site. The work efficiency was compared between the applied fleet management system and a conventional earthwork method. In case of Eunam Industrial Complex Site shown in Fig. 6 when cluser allocation was made, the work rate per hour improved 10\%. In Fig. 7, Onsan Industrial Complex Site when the first cluster was achieved, the work rate per hour increased 5\%. In Fig. 8, Damyang Advanced Industrial Complex Site when cluster allocation was made, the work rate per hour increased $10 \%$ when reallocation was achieved, the work rate per hour increased $26 \%$. Therefore, this fleet management system was proved to have high field applicability. 
(a)

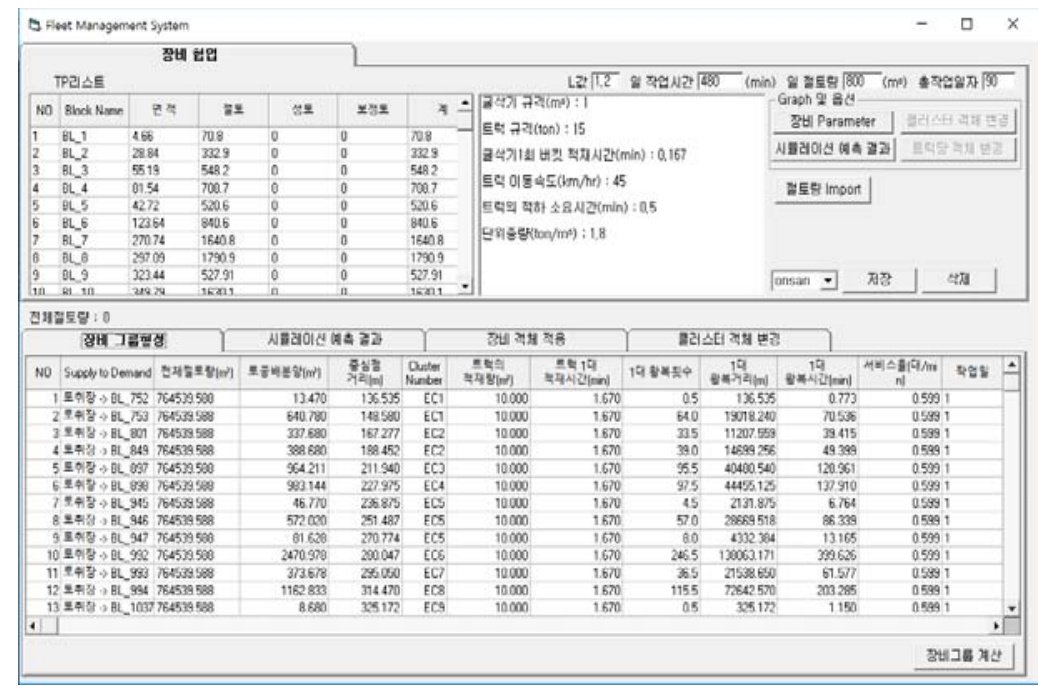

(b)

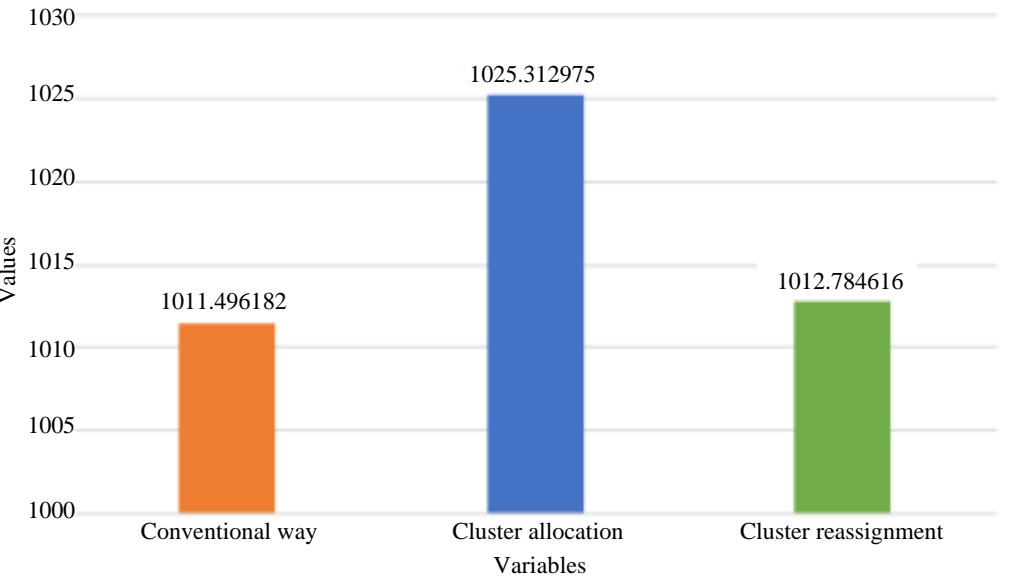

Fig. 7: a, b) The result of the application of fleet management system to Onsan Industrial Complex Site; Work per cluster average hour $\left(\mathrm{m}^{3} / \mathrm{h}\right)$

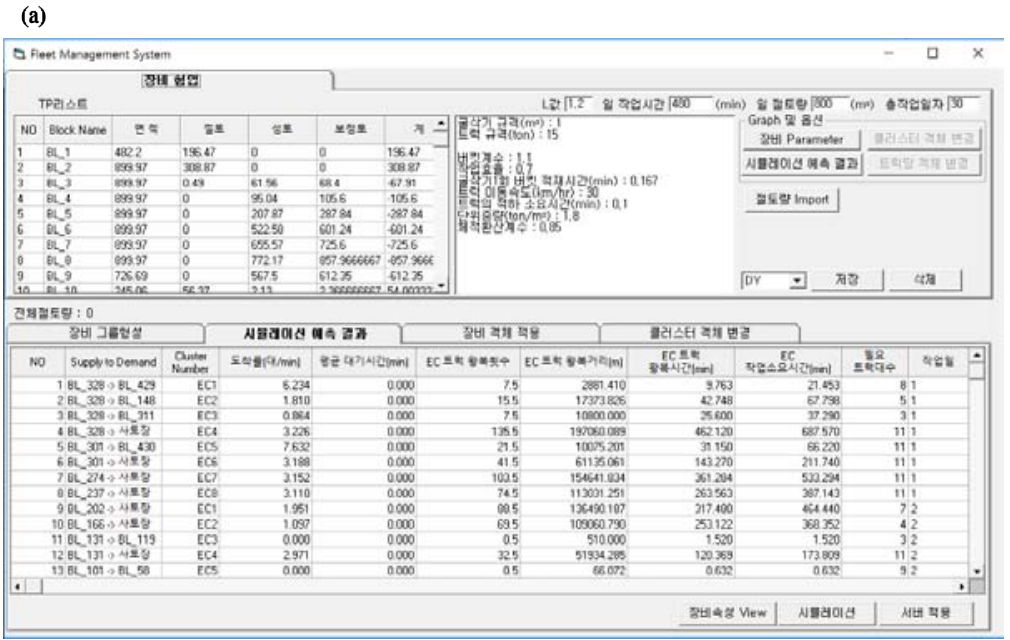

Fig. 8: Continue 


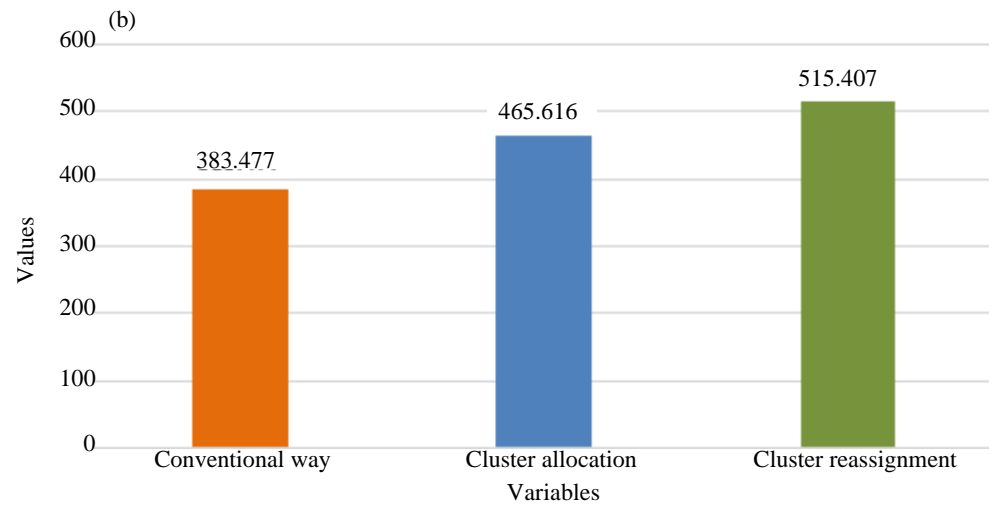

Fig. 8: a, b) The result of the application of fleet management system to Damyang Advanced Industrial Complex Site; Work per cluster average hour $\left(\mathrm{m}^{3} / \mathrm{h}\right)$

\section{CONCLUSION}

One of the causes for lowering productivity at a construction site is the operation based on a construction manager's intuition. To solve the problem, much research has been conducted. A case in point is research on a fleet management system. Through continuous research, the developed system has been improved. Previous studies proposed a method for each equipment's works. This study proposed a plan for providing a work plan and work state information to each construction equipment operator and using them when a lot of and multiple types of construction equipment are applied. In addition, the improved system is offered to actual construction sites and the process of collecting field operators' heuristic aspects continuously is performed. The fleet management system suggests a moving path according to earthwork planning in order for the optimal cooperation of construction equipment and shows grouping information to increase the work time of each equipment. Nevertheless, something to improve in a conventional algorithm continues to be drawn in the process of earth distribution. For improvements, a density based algorithm was executed, so as to improvement a conventional system which failed to make earth distribution in each different distance. By providing the function of tracking a position and a work volume in real time at a site, the system tries to achieve efficient work performance at a construction site. The improved fleet management system was able to provide applicable and easy information to equipment operators so that its field applicability was improved. It will be useful to improve productivity at a construction site and field manager's decision making.

\section{RECOMMENDATIONS}

In the future research, it will be necessary to make confirmation at a variety of construction sites, to improve the use environments of the fleet management system and thereby to examine efficiency of the system at a lot of and multiple types of construction sites.

\section{REFERENCES}

Ahn, S.H., S.K. Kim and K.H. Lee, 2016. Development of a fleet management system for cooperation among construction equipment. J. Korean Soc. Civil Eng., 36: 573-586.

Anonymus, 2015. Berkeley lab promotes low-corbon cities in China. Energy Analysis \& Environmental Impacts Division News, US Department of Energy, James V. Forrestal Building, Washington, DC., USA.

Baek, H.G., S.H. Kang and J.W. Seo, 2015. An earthwork districting model for large construction projects. J. Korean Soc. Civil Eng., 35: 715-723.

Easa, S.M., 1992. Estimating earthwork volumes of curved roadways: Mathematical model. J. Trans. Eng., 118: 834-849.

Easa, S.M., 1993. Smooth boundary approximation for directly computing irregular area. J. Surv. Eng., 119: 86-101.

Easa, S.M., 1998. Smooth surface approximation for computing pit excavation volume. J. Surv. Eng., 124: 125-133.

Kim, S.K. and S.Y. Lim, 2017. [A study on the improvement of a fleet management system for construction equipment (In Korean)]. J. Korean Soc. Civ. Eng., 37: 1063-1076.

Kim, S.K., 2014. A multi-agent based cooperation system for an intelligent earthwork. J. Korean Soc. Civil Eng., 34: 1609-1623.

Kim, S.K., J.W. Seo and J.S. Russell, 2012. Intelligent navigation strategies for an automated earthwork system. Autom. Constr., 21: 132-147. 